\title{
Nicardipine HCL: clinical experience in patients undergoing anaesthesia for intracranial aneurysm clipping
}

David S. Warner MD, ${ }^{1}$ Martin D. Sokoll MD, Mazen Maktabi MD, ${ }^{1}$ John C. Godersky MD, ${ }^{2}$ Harold P. Adams MD $^{3}$ effects with respect to maintenance of intraoperative haemodynamic stability despite continuous antivasospasm therapy with this vasodilator.

Among hospitalized patients with aneurysmal subarachnoid haemorrhage (SAH), the leading cause of morbidity and mortality is cerebral vasospasm. ${ }^{1}$ Current experimental approaches toward pharmacologic treatment of vasospasm have focused on the use of agents which inhibit calcium entry into vascular smooth muscle. ${ }^{2}$ One such agent, nicardipine $\mathrm{HCl}$, a dihydropyridine derivative, has been proposed to have a potentially beneficial action because of its preferential cerebrovascular activity. ${ }^{3}$ Although nicardipine-induced cerebrovascular relaxation has been documented in cats subjected to experimental vasospasm, ${ }^{4}$ the safety and efficacy of nicardipine therapy in treating human vasospasm remains under investigation. $^{5}$

Our institution was recently involved in a nicardipine dose-escalation study designed to determine maximally tolerated IV doses in patients with aneurysmal SAH. ${ }^{5}$ Nicardipine is a potent peripheral vasodilator ${ }^{3,6}$ Because current therapy dictates continuous IV administration of this agent throughout the perioperative period, ${ }^{5,7}$ untoward haemodynamic interactions between nicardipine and anaesthetic management of patients for aneurysm surgery are possible. The purpose of this study, therefore, was not so much to seek physiologic mechanisms by which nicardipine might interact with anaesthetic agents, but rather to determine if titration of doses of routine anaesthetic drugs and adjuvants used during craniotomy for aneurysm clipping would allow a stable haemodynamic state in the presence of this vasodilator.

\section{Methods}

This study was approved by our institutional human investigation committee and written consent was obtained from all participating patients. All patients were ASA 
physical status II or III and had angiographically documented intracranial aneurysm(s) with SAH. The doseescalation study involved successive groups of patients who received progressively higher doses of nicardipine $\mathrm{HCl}$ (Syntex, Palo Alto, CA) at a constant infusion rate. ${ }^{5}$ Our study was initiated with the group receiving the maximal dose dictated by the protocol $\left(0.15 \mathrm{mg} \cdot \mathrm{kg}^{-1}\right.$ $\cdot \mathrm{hr}^{-1}$ ) which remained unchanged throughout the perioperative period. Thirteen patients receiving this dose of nicardipine were compared with eleven who received none (controls). Patients designated to receive nicardipine were so chosen by conforming to a strict protocol allowing participation in the dose-escalation study. ${ }^{5}$ Infusion of nicardipine was commenced immediately after angiographic evidence for an intracranial aneurysm was obtained. The control patients were contemporaries who did not enter that study.

All patients were brought to the operating room unpremedicated where arterial (radial) and pulmonary artery (via basilac vein) catheters were placed. Awake (pre-induction) haemodynamic measurements included systolic, diastolic, and mean arterial pressure (MAP), heart rate (HR), central venous pressure (CVP), mean pulmonary artery pressure (PAP), and mean pulmonary artery capillary wedge pressure (PACWP). Cardiac output, as determined by thermodilution in triplicate, allowed calculation of cardiac index $(\mathrm{Cl})$ and systemic vascular resistance (SVR). Blood samples were drawn for determination of arterial and mixed venous blood gases, as well as plasma nicardipine concentration (Syntex, Palo Alto, CA).

Anaesthesia was then induced with thiopentone (4 $\mathrm{mg} \cdot \mathrm{kg}^{-1}$ ), morphine sulphate $\left(0.25 \mathrm{mg} \cdot \mathrm{kg}^{-1}\right)$, and pancuronium $\left(0.1 \mathrm{mg} \cdot \mathrm{kg}^{-1}\right) \mathrm{IV}$. When the airway was controlled with mask ventilation, hyperventilation was begun $\left(\mathrm{PaCO}_{2}=25-30 \mathrm{mmHg}\right.$ ) and nitrous oxide ( 70 per cent) was added to the inspiratory gas mixture. Isoflurane (0.2-3.0 per cent delivered) was administered as required to maintain systolic blood pressure $<120 \mathrm{mmHg}$. After complete neuromuscular blockade was achieved, the patients ${ }^{*}$ tracheas were intubated and 10 min later the above haemodynamic and blood gas measurements were repeated. All patients then received mannitol $(0.5-1.0$ gram $\cdot \mathrm{kg}^{-1}$ ) IV over $20 \mathrm{~min}$ with the measurements repeated $10 \mathrm{~min}$ later. Induced hypotension, as indicated by surgical requirements, was achieved with IV sodium nitroprusside (SNP) infusion. Haemodynamic variables and blood gases were assessed with MAP $=60$ and 50 $\mathrm{mmHg}$ respectively. After successful surgical clipping of the aneurysm, SNP was discontinued and $45 \mathrm{~min}$ later final measurements were obtained during closure of the galea. In the post-hypotensive interval and during emergence from anaesthesia, IV propranolol and hydralazine were administered as required to maintain heart rate $<90$
TABLE I Demographic data for nicardipine-treared and control patients

\begin{tabular}{lcc}
\hline & Control & Nicardipine \\
\hline Age (years) & $52 \pm 11$ & $45 \pm 12$ \\
Sex (M/F) & $4 / 7$ & $5 / 8$ \\
Days s/p SAH & $9 \pm 7$ & $8 \pm 6$ \\
\hline
\end{tabular}

bpm and systolic BP $<140 \mathrm{mmHg}$ respectively. Total IV fluids administered during the anaesthetic as well as estimated surgical blood loss were recorded. Data were analyzed by Chi-square analysis, unpaired student's $t$-test, and 2-way analysis of variance (treatment group $x$ anaesthetic interval) with post-hoc multiple comparison testing where indicated by a significant $F$ ratio. Values are reported as mean $\pm S D$ with significance assumed when $P<0.05$.

\section{Results}

There were no statistically significant differences between groups with respect to age, sex, or the interval (days) between onset of SAH symptoms and surgery (Table I). Analysis of blood gases (arterial and mixed venous) was also without difference between groups at each interval throughout the study period. Prior to the induction of anaesthesia, MAP and SVR were lower (P < $0.05)$ while $\mathrm{Cl}$ was higher $(\mathrm{P}<0.01)$ in nicardipinetreated patients versus untreated controls (Table II). In contrast, heart rate, PACWP, PAP, and CVP values were similar between groups. At $10 \mathrm{~min}$ post-intubation, values for all variables were similar between groups with the exception of CVP, PAP, and PACWP which were greater $(P<0.01)$ in the nicardipine-treated patients. In the nicardipine group MAP was unchanged from preinduction values (Figure). To the contrary, MAP was reduced in control patients when compared with preinduction values $(P<0.05)$. Unintentional hypotension during the induction sequence (defined as systolic BP $<90 \mathrm{mmHg}$ ) occurred with similar frequency in nicardipine-treated patients ( 3 of 13) vs control patients (3 of II). During the same interval, a systolic BP $<80$ $\mathrm{mmHg}$ occurred in no patient in either group.

During the induction and intubation sequence, the frequency that isoflurane administration was required to manage systolic blood pressure was significantly less ( $P$ $<0.01$ ) in nicardipine-treated patients ( 3 of 13 patients). In these three patients, the maximum isoflurane concentration derived was 0.5 per cent. In contrast, 9 of 11 control patients received isoflurane with doses administered varying from 0.5 to 3 per cent. Despite this, MAP was similar between groups (nicardipine $=78 \pm 16$ $\mathrm{mmHg}$; control $=74 \pm 15 \mathrm{mmHg}$ ). Ten min pastmannitol infusion, values were similar between groups for all variables measured. During SNP-induced hypoten- 
TABLE II Haemodynamic values throughout anaesthesia for intracranial aneurysm surgery in patients with and without nicardipine therapy for vasospasm

\begin{tabular}{|c|c|c|c|c|c|c|}
\hline & $\begin{array}{l}H R \\
\left(\text { beats } \cdot \min ^{-1}\right)\end{array}$ & $\begin{array}{l}M A P \\
(m m H g)\end{array}$ & $\begin{array}{l}\text { PACWP } \\
(m m H g)\end{array}$ & $\begin{array}{l}C V P \\
(m m H g)\end{array}$ & $\begin{array}{l}C I \\
\left(L \cdot \min ^{-1} \cdot m^{-2}\right)\end{array}$ & $\begin{array}{l}\text { SVR } \\
\left(\text { dynes } \cdot \mathrm{sec}^{\prime} \mathrm{cm}^{-5}\right)\end{array}$ \\
\hline \multicolumn{7}{|c|}{ Pre-Induction } \\
\hline Nicardipine & $82 \pm 13$ & $86 \pm 10^{\mathrm{a}}$ & $14 \pm 6$ & $8 \pm 5$ & $5.67 \pm 1.30^{\mathrm{b}}$ & $647 \pm 227^{\mathrm{b}}$ \\
\hline Control & $78 \pm 16$ & $99 \pm 14$ & $12 \pm 4$ & $7 \pm 3$ & $3.99 \pm 0.73$ & $1141 \pm 404$ \\
\hline \multicolumn{7}{|c|}{ Post-intubation (10 min) } \\
\hline Nicardipine & $86 \pm 21$ & $78=16$ & $15 \pm 5^{b}$ & $10 \pm 5^{b}$ & $4.60 \pm 2.10$ & $747 \pm 237$ \\
\hline Control & $83 \pm 18$ & $74=15^{\mathrm{c}}$ & $8 \pm 3$ & $5 \pm 2$ & $3.26 \pm 1.32$ & $954=336$ \\
\hline \multicolumn{7}{|c|}{ Post-mannitol (10 min) } \\
\hline Nicardipine & $74 \pm 15$ & $75 \pm 7$ & $14 \pm 6$ & $9 \pm 5$ & $4.48 \pm 1.42$ & $682 \pm 200$ \\
\hline Control & $77 \pm 15$ & $71 \pm 16$ & $13 \pm 6$ & $8 \pm 4$ & $3.72 \pm 0.98$ & $815=324$ \\
\hline \multicolumn{7}{|c|}{$M A P=60 \mathrm{mmHg}_{\mathrm{g}}$} \\
\hline Nicardipine & $70 \pm 15$ & $60 \pm 1$ & $10 \pm 4$ & $6 \pm 4$ & $4.54 \pm 1.29^{n}$ & $6.14 \pm 271$ \\
\hline Control & $72 \pm 14$ & $61 \pm 1$ & $8 \pm 5$ & $4 \pm 4$ & $3.20 \pm 0.92$ & $829 \pm 248$ \\
\hline \multicolumn{7}{|c|}{$M A P=50 \mathrm{mmHg}$} \\
\hline Nicardipine & $83 \pm 10$ & $50 \pm 1$ & $9 \pm 4$ & $6 \pm 4$ & $4.33 \pm 1.30^{3}$ & $545 \pm 294$ \\
\hline Control & $76 \pm 14$ & $50 \pm 1$ & $7 \pm 5$ & $5 \pm 4$ & $3.18 \pm 0.93$ & $669 \pm 203$ \\
\hline \multicolumn{7}{|c|}{ Craniotomy closure } \\
\hline Nicardipine & $75 \pm 11$ & $82 \pm 8$ & $13 \pm 3$ & $9 \pm 5$ & $3.47 \pm 1.17$ & $935 \pm 4.47$ \\
\hline Control & $75 \pm 11$ & $84 \pm 16$ & $11 \pm 4$ & $8 \pm 3$ & $3.72 \pm 1.53$ & $1008 \pm 363$ \\
\hline
\end{tabular}

Values $=$ mean \pm SD. $\quad a=P<0.05 ; b=P<0.01$ comparing nicardipine $(n=13)$ vs control $(n=11)$ groups at respective perioperative intervals. $\mathrm{c}=\mathrm{P}<0.05$ comparing pre-induction to post-intubation values within treatment groups.

sion (MAP $=60$ and $50 \mathrm{mmHg}$ ), haemodynamic values remained comparable between groups with the exception of $\mathrm{CI}$ which was higher in the nicardipine group $(\mathrm{P}<$ 0.05 ). During craniotomy closure, no differences between groups could be detected in any of the variables measured. Pre-induction plasma nicardipine levels were $228 \pm 56 \mathrm{ng} \cdot \mathrm{ml}^{-1}$ in nicardipine-treated patients.

Total IV fluid volume administered was significantly greater $(\mathrm{P}<0.05)$ in the nicardipine group $(2.4 \pm 0.3 \mathrm{~L})$ vs controls $(1.5 \pm 0.4 \mathrm{~L})$ despite a similar estimated surgical blood loss between groups (nicardipine $=372 \pm$ $213 \mathrm{ml}$; control $=312 \pm 114 \mathrm{ml}$ ). No patients required administration of sympathomimetic agents for blood pressure support. Total hydralazine and propranolol administered during craniotomy closure were not different between groups (nicardipine: $7.7 \pm 12 \mathrm{mg}, 1.2 \pm 1.3$ $\mathrm{mg}$; control: $11.4 \pm 16 \mathrm{mg}, 1.4 \pm 1.7 \mathrm{mg}$ respectively).

\section{Discussion}

Strict control of arterial blood pressure is a necessary component of anaesthesia for intracranial aneurysm surgery. Although the haemodynamic effects of nicardipine $\mathrm{HCl}$ have been widely studied in conscious humans, reports on the interaction between this drug and haemodynamic variables in the anaesthetized patient have been few. ${ }^{9,10}$ Kishi et al. observed that bolus injection of nicardipine $(0.5-1.5 \mathrm{mg})$ is safe and effective in reducing acute intraoperative hypertension. ${ }^{9}$ However, the doses administered in their study were significantly less than those received by patients in our study. In the dog, Hysing et al. found that hypotensive properties of nicardipine and isoflurane were additive resulting mainly from isofluraneinduced inhibition of the reflex tachycardia elicited by nicardipine. ${ }^{11}$ Using retrospective analysis, Stullken et al. found that nimodipine, another dihydropyridine calcium-antagonist, resulted in reduced arterial blood pressure throughout anaesthetics given for aneurysm surgery when compared with untreated patients. ${ }^{12}$ In addition to these haemodynamic considerations, numerous other interactions between calcium antagonists and anaesthetic agents have been reported. ${ }^{13.14}$ Because the frequency of administration of nicardipine $\mathrm{HCl}$ to treat cerebral vasospasm is expected to increase, ${ }^{5}$ we felt that preliminary information on the safety of administering anaesthesia to patients with high-dose nicardipine infusion in progress should be obtained. Our results indicate that the presence of nicardipine had only minor significance in delivering a successful anaesthetic.

Prior to the induction of anaesthesia, nicardipinetreated SAH patients were found to have significantly lower MAP and SVR while CI was significantly higher than was observed in untreated controls. Similar 

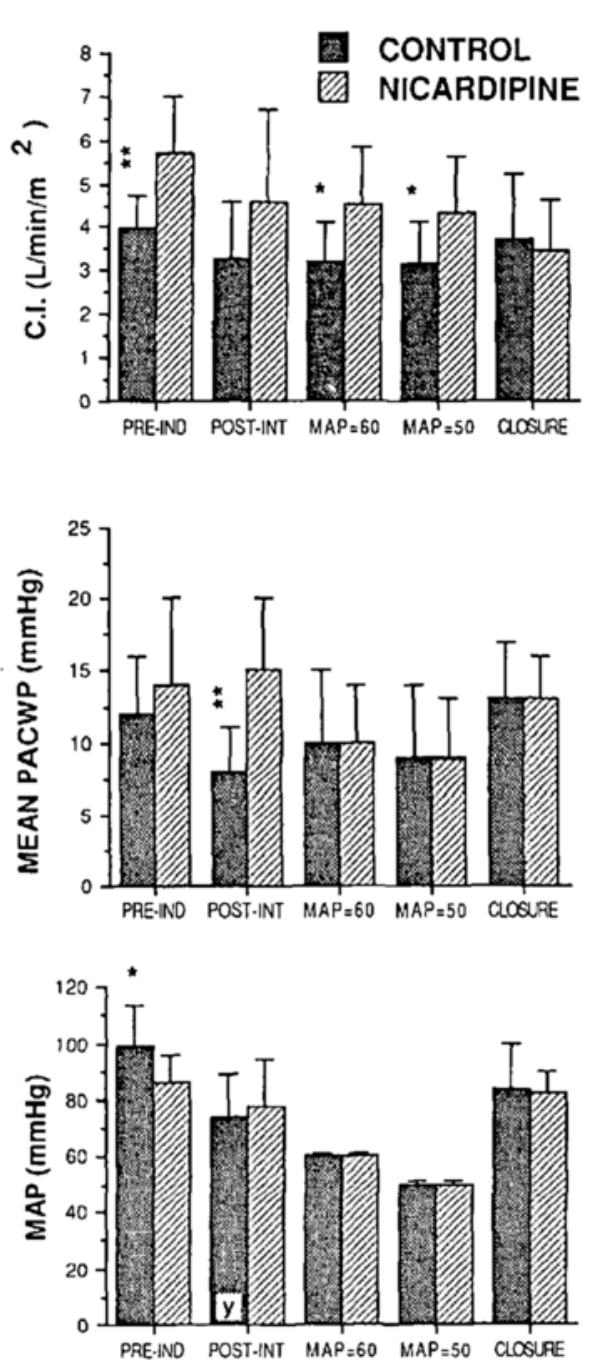

Anesthetic Interval

FIGURE Cardiac index (CI), mean pulmonary artery capillary wedge pressure (PACWP), and mean arterial pressure (MAP) at various stages of the anaesthetic (PRE-IND $=$ awake; POST-INT $=10 \mathrm{~min}$ after intubation; $\mathrm{MAP}=60 \mathrm{mmHg}$ and $50 \mathrm{mmHg}$ during induced hypotension; during galeal closure). Values $=$ mean \pm SD $*=\mathrm{P}<0.05 ; * *=\mathrm{P}<0.01$ comparing nicardipine vs control patients at each anaesthetic interval. $y=\mathbf{P}<0.05$ comparing preinduction to post-inubation values within the control group. nicardipine-induced haemodynamic changes have been reported in awake healthy human volunteers. ${ }^{15}$ These changes in our patients were not accompanied by tachycardia and this differs from previous reports in awake patients. ${ }^{8,16.17}$ Those studies, however, evaluated acute responses to the administration of nicardipine while in our patients the average duration of nicardipine administration was seven days before surgery. Resetting of the baroreflex with recovery from tachycardia during chronic administration of nicardipine has been reported previously. ${ }^{18,19}$

Induction of anaesthesia and tracheal intubation resulted in similar values for CI, SVR, and MAP between groups. Although MAP in the nicardipine group was statistically unchanged from awake values, MAP was decreased by 25 per cent $(P<0.05)$ over the same interval in control patients. At the same time CVP, PACWP, and PAP were significantly greater in nicardipine versus control patients. Although relatively large standard deviations in CI and SVR preclude elucidation of the underlying mechanisms for these differences, our clinical impression is that the stability of MAP and greater venous pressures in the nicardipine group were due to restriction of isoflurane administration as well as IV fluid therapy administered during the induction sequence. The latter point is supported by the observation that nicardipine patients received significantly more fluids during the course of the anaesthetic.

Induced hypotension was well tolerated by patients in both groups. Unfortunately, we did not quantitate the SNP dose required to achieve MAP $=50$ and $60 \mathrm{mmHg}$ for comparison between groups. However, both groups demonstrated a rapid recovery from hypotension upon discontinuation of nitroprusside and dosage requirements for hydralazine and propranolol to treat rebound hypertension were similar between groups.

In summary, our experience with nicardipine $\mathrm{HCl}$ during anaesthesia for intracranial aneurysm surgery revealed no major untoward effects in maintenance of haemodynamic stability despite the presence of high doses of this vasodilator. Conclusions from our investigation are limited to the specific anaesthetic regimen described, but the data suggest that haemodynamic control can be readily achieved during anaesthesia for intracranial aneurysm surgery despite continuous antivasospasm therapy with nicardipine $\mathrm{HCl}$.

\section{References}

1 Heros RC, Zervas NT, Varsos V. Cerebral vasospasm after subarachnoid hemorthage. An update. Ann Neurol 1983; 14: 599-608.

2 Wilkins RN. Attempts at prevention or treatment of 
intracranial arterial spasm. An update. Neurosurg 1986; 18: 808-25.

3 Takenaka $T$, Usuda $S$, Nomura $T$, Maeno $H$, Sado $T$. Vasodilator profile of a new 1,4-dihydropyridine derivative, 2,6-dimethyl 4-(3-nitrophenyl)-1,4dihydropyridine-3,5-dicarboxylic acid 3-[2-(N-benzyl$\mathrm{N}$-methyl-amine)]-ethyl ester 5-methyl ester hydrochloride (YC-93). Arzneimittel-Forschung 1976; 26: 2172-8.

4 Hand J. Yoneda S, Koyama T, Matsuda M, Handa $H$. Experimental cerebral vasospasm in cats: modification by a new synthetic vasodilator YC-93. Surg Neurol 1975; 3: 195-9.

5 Flamm ES, Adams HP, Beck DW et al. A dose escalation study of intravenous nicardipine in patients with aneurysmal subarachnoid hemorrhage. J Neurosurg 1988; 68; $393-400$.

6 Rousseau MF, Etienne J, Van Mechelen H, Veriter C, Pouleur H. Hemodynamic and cardiac effects of nicardipine in patients with coronary artery disease. J Cardiovasc Pharm 1984; 6: 833-9.

7 Kassell NF, Drake CG. Timing of aneurysm surgery. Neurosurg 1982; 10: 514-9.

8 Sorkin EM, Clissold SP. Nicardipine; a review of its pharmacodynamic and pharmacokinetic properties, and therapeutic efficacy, in the treatment of angina pectoris, hypertension, and related cardiovascular disorders. Drugs 1987; 33: 296-345.

9 Kishi $Y$. Okumura F, Furuya $H$. Haemodynamic effects of nicardipine hydrochloride: studies during its use to control acute hypertension in anaesthetized patients. $\mathrm{Br} J$ Anaesth 1984; 56: 1003-6.

10 Arai $T$, Hatano $Y$, Ishida $H$, Mori $K$. Use of nicardipine in the anesthetic management of pheochromocytoma. Anesth Analg 1986; 65: 706-8.

1) Hysing ES, Chelly JE, Darrsot MF, Hartley $C$, Merin $R G$. Cardiovascular effects of, and interactions between, calcium blocking drugs and anesthetics in chronically instrumented dog. III. Nicardipine and isoflurane. Anesthesiology 1986; 65: 385-91.

12 Stulken EH, Johnston WE, Prough DS, Balestrieri FJ, $M c$ Whorter $J M$. Implications of nimodipine prophylax is of cerebral vasospasm or anesthetic management during intracranial aneurysm clipping. J Neurosurg 1985; 62: 200-5.

13 Jenkins LC, Scoates PJ. Anaesthetic implications of calcium channel blockers. Can Anaesth Soc J 1985; 32: 436-47.

14 Merin $R G$. Calcium channel blocking drugs and anesthetics: is the drug interaction beneficial or detrimental? Anesthesiology 1987; 66: 111-3.

15 McCredie RM, McKenzie WB, McGill DA. The acute haemodynamic effects of oral nicardipine. Brit J of Clin Pharm (Suppl. 1) 1986; 20: 163S-8S.
16 Aoki $K$, Kawaguchi Y, Sato K, Koado S, Yamamoto $M$. Clinical and pharmacological properties of calcium antagonists in essential hypertension in humans and spontaneously hypertensive rats. J Cardiovasc Pharm 1982; 4 (Suppl. 3): S298-S302.

17 Iliopoalou A, Turner P, Warringron SJ. Acute haemodynamic effects of a new calcium antagonist, nicardipine, in man. A comparison with nifedipine. Brit J Clin Pharm 1983; 15: 59-66.

18 Young MA, Watson RDS, Littler WA. Baroreflex setting and sensitivity after acule and chronic nicardipine therapy, Clin Sci 1984; 66: 233-5.

19 Fujotu $T$, Noda $H$. Hemodynamic changes assaciated with long term anti-hypertensive therapy with a new calcium antagonist. Jap Heart Journal 1983; 24: 587-93.

\section{Résumé}

Des études antérieures ont rapporté des intéractions hémodynamiques entre les antagonistes du calcium dihydropyridine et l'anesthésie générale. Durant l'anesthésie pour résection d'un anéurysme intracrânien, on a comparé d'ume façon prospective les valeurs hémodynamiques obtenues chez treize patients ayant été traités avec la nicardipine $\mathrm{HCl}$ $\left(0.15 \mathrm{mg} \cdot \mathrm{kg}^{-1} / \mathrm{hr}^{-1} \mathrm{IV}\right)$ pour vasospasme cérébral avec des valeurs obtenues chez onze patients contrôle non traités. Avant l'induction, les patients traités à la nicardipine avaient une élévation significative de la valeur moyenne $\pm S D$ de l'index cardiaque $\left(5.67 \pm 1.30 \mathrm{vs} 3.99 \pm 0.73 \mathrm{~L} \cdot \mathrm{min}^{-1} \mathrm{~m}^{-2}\right)$ alors que la pression artérielle moyenne $(86 \pm 10 \mathrm{ws} 99 \pm 14 \mathrm{mmHg}$ ) et la résistance vasculaire systémique $(647 \pm 227$ vs $1 / 41 \pm$ 404 dynes $\cdot \mathrm{sec}^{-1} \cdot \mathrm{cm}^{-5}$ ) étaient diminuées. La fréquence cardiaque, la pression veineuse centrale et la pression bloquée de l'artère pulmonaire étaient similaires dans les deux groupes. L'induction de l'anesthésie et l'intubation ont produit des valeurs hémodynamiques similaires entre les groupes à l'exception de la pression veineuse centrale (10 15 vs $4 \pm 2$ $\mathrm{mmHg}$ ) et la pression bloquée de l'artère pulmonaire $(15 \pm 5 \mathrm{vs}$ $8 \pm 3 \mathrm{mmHg}$ ) qui étaient élevées dans le groupe nicardipine ( $P$ $<0.01)$. La perfusion de mannitol et l'hypotension contrôlée ont amené des réponses hémodynamiques quasi identiques darts les deux groupes. Les patients traités à la nicardipine ont requis plus de liquide lors de la procédure chirurgicale $12.4 \pm 0.3 \mathrm{~L}$ vs $1.5 \pm 0.4 L, P<0.05$ ) et avaient tendance à recevoir moins d'isoflurane supplémentaire lors d'une anesthésie au sulfate de morphinelprotoxyde d'azote $(P<0.01)$. En résumé, notre expérience avec $\mathrm{HCl}$ nicardipine $n^{*}$ a pas démontré d'effets secondaires sur la stabilité hémodynamique peropératoire malgré la continuation de la thérapie antispasmadique avec ce vasodilatateur. 